\title{
Tumor Recurrence after Negative Pressure Wound Therapy: An Alert Call
}

\author{
Patricio Andrades*, Manuel Figueroa, Sergio Sepúlveda, Susana Benitez, Cristian Erazo, \\ Stefan Danilla \\ Division of Plastic Surgery, Department of Surgery, University of Chile Clinical Hospital, Santiago, Chile \\ Email: ${ }^{\text {pandrades@uchile.cl }}$
}

Received 5 April 2014; revised 4 May 2014; accepted 3 June 2014

Copyright @ 2014 by authors and Scientific Research Publishing Inc.

This work is licensed under the Creative Commons Attribution International License (CC BY). http://creativecommons.org/licenses/by/4.0/

(c) (i) Open Access

\begin{abstract}
In this report, we present a 22-year-old patient with soft tissue sarcoma of the lower extremity that developed wound dehiscence after surgery. Biopsy demonstrated negative margins for cancer. He was treated with negative pressure wound therapy for 6 weeks and started to present increased wound exudates, local pain and proliferating tissue that was positive for tumor recurrence. Consequently he underwent lower extremity amputation with hip disarticulation by the orthopedic team. Although we cannot determine with certainty a full causative relationship, it seems prudent to advise cautious use of negative pressure wound therapy in oncologic related wound beds.
\end{abstract}

\section{Keywords}

Negative Pressure Wound Therapy, Vacuum Assisted Closure, Cancer, Recurrence

\section{Introduction}

The use of negative pressure wound therapy has become massive in recent years. Management of complex wounds both acute and chronic, particularly in diabetic foot ulcers, post-traumatic wounds and vascular ulcers, has been extensively performed using this system by almost every surgical specialty. Unfortunately recent systemic reviews have not been able to demonstrate high level of evidence supporting the superiority of negative wound therapy over conventional treatment [1] [2]. In addition, many adverse effects such as infection, skin irritation, foreign body waste, skin necrosis, painful dressing changes, difficult daily wound evaluation, fistula development, massive bleeding and a possible increased in the rate of mortality have been reported [3]-[6]. In this brief communication, we present a case report where another serious complication occurred and may be related to vacuum assisted closure.

${ }^{*}$ Corresponding author.

How to cite this paper: Andrades, P., Figueroa, M., Sepúlveda, S., Benitez, S., Erazo, C. and Danilla, S. (2014) Tumor Recurrence after Negative Pressure Wound Therapy: An Alert Call. Case Reports in Clinical Medicine, 3, 350-352.

http://dx.doi.org/10.4236/crcm.2014.36077 


\section{Case Report}

A 22-year-old male patient with a history of soft tissue high grade fusocellular sarcoma of the right thigh measuring $23 \times 10 \times 9 \mathrm{~cm}$, was resected with negative margins in 2009 at another institution. A local recurrence was detected in 2010 and the patient underwent a new surgical resection and adjuvant radiotherapy completing 5000 cGray in daily sessions of 200 cGray for 2 months. He was admitted at our hospital in January 2012 with severe malnutrition and a new local tumor recurrence. The Cancer Committee decided a new surgical resection that required femoral vessels excision followed by femoro-popliteal by-pass with PTFE prosthesis and primary wound closure. Posterior biopsy demonstrated negative surgical margins for tumor. In the early postoperative period the patient developed mid and distal wound dehiscence with partial exposure of the vascular prosthesis and the plastic surgery team was consulted.

Considering the poor general conditions of the patient, flap closure was delay and negative pressure wound therapy was set in a continuous manner between 100 or $120 \mathrm{mmHg}$ with changes every 4 to 5 days. After 6 weeks of multidisciplinary management including nutritional support, physical therapy, negative pressure wound therapy and psychiatric surveillance, adequate general and local conditions were achieved and surgery was plan in order to cover the remaining defect. But the patient started to present increased wound exudates, local pain and an exaggerated and friable proliferation during the following 2 weeks (Figure 1). Biopsy of the proliferating tissue revealed a new tumor recurrence and lower extremity amputation with hip disarticulation was performed by the orthopedic team.

\section{Discussion}

At present there is no evidence of malignant recurrence after negative pressure wound therapy, on the contrary, the use of this type of treatment for the management of complicated wound healing in sarcoma patients following tumor surgery has been reported to be safe and effective [7]. However, if the physiologic and molecular bases of negative pressure and tissue expansion are analyzed, we would realize that its use may be hazardous in

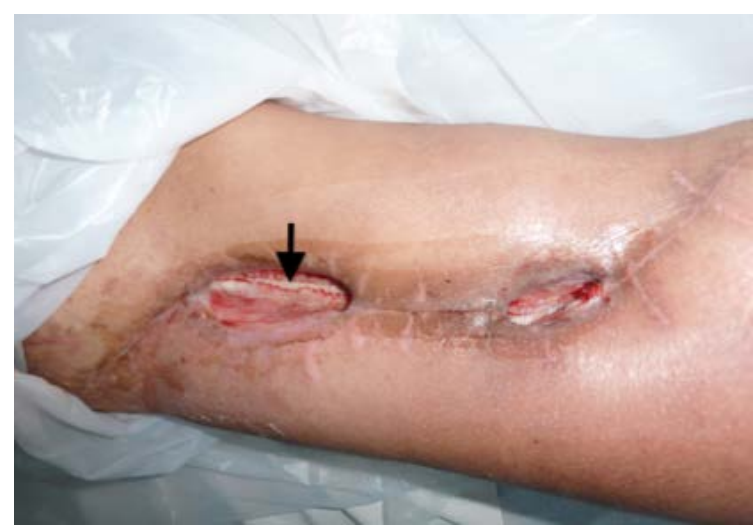

(a)

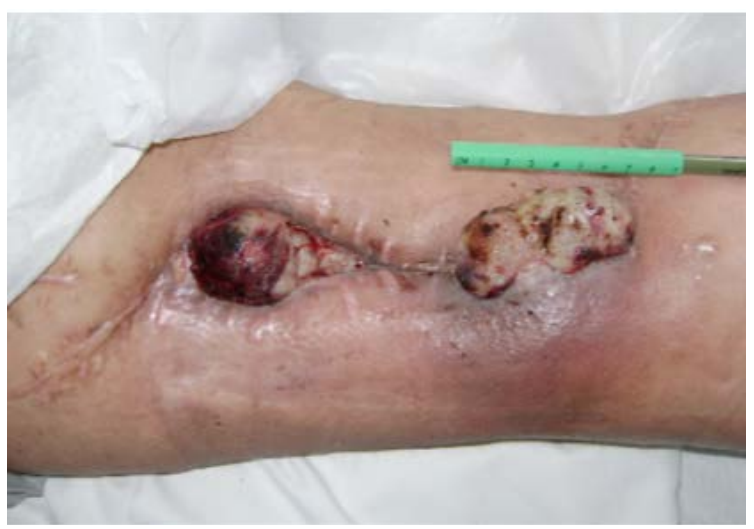

(b)

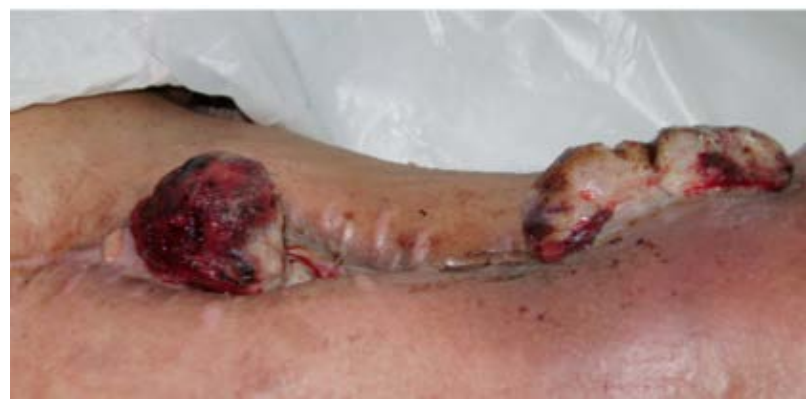

(c)

Figure 1. (a) Right thigh with surgical wound dehiscence and partial exposure of vascular prosthesis (black arrow); (b) and (c) Tumor recurrence 2 months after healing with vacuum assisted closure. 
oncologic patients. The mechanical stress imposed by negative pressure generates mechano-transduction signals from different kinds of membrane proteins that promote the expression of genes that regulate cell proliferation [8]. In other words, stretching cells stimulate them to grow and multiply [9]. While this effect may be welcome in acute or chronic wounds promoting healing, in oncology patients the stimulation of cellular hyperplasia in tissues that have lost self-control can be dangerous. The use of negative pressure in this setting may stimulate the appearance of a rapid local recurrence despite of negative margins, as in the case reported.

\section{Conclusion}

Although we cannot determine with certainty a full causative relationship between vacuum assisted closure and cancer recurrence in this case, we can say that it at least help in the fast development of a recurrent tumor. In our opinion, it seems prudent to advise cautious use of negative pressure wound therapy in oncologic related wound beds.

\section{Conflicts of Interests}

None of the authors has a financial interest in any of the products, devices, or drugs mentioned in this manuscript.

\section{References}

[1] Ubbink, D.T., Westerbos, S.J., Nelson, E.A., et al. (2008) A Systematic Review of Topical Negative Pressure Therapy for Acute and Chronic Wounds. The British Journal of Surgery, 95, 685-692. http://dx.doi.org/10.1002/bjs.6238

[2] Webster, J., Scuffham, P., Sherriff, K.L., et al. (2012) Negative Pressure Wound Therapy for Skin Grafts and Surgical Wounds Healing by Primary Intention. Cochrane Database of Systematic Reviews, 4, Article ID: CD009261.

[3] Hallock, G.G. (2005) Top Ten Reasons to Hate the “V.A.C.”. Plastic and Reconstructive Surgery, 116, 1839. http://dx.doi.org/10.1097/01.prs.0000188840.06911.06

[4] Mulgrew, S., Khoo, A., Newton, R.M., et al. (2011) Pressure Necrosis Secondary to Negative Pressure Dressing. Annals of the Royal College of Surgeons of England, 93, e27-e28. http://dx.doi.org/10.1308/147870811X580433

[5] Van Wingerden, J.J., Segers, P. and Jekel, L. (2011) Major Bleeding during Negative Pressure Wound/V.A.C.(R)— Therapy for Postsurgical Deep Sternal Wound Infection-A Critical Appraisal. Journal of Cardiothoracic Surgery, 6, 121. http://dx.doi.org/10.1186/1749-8090-6-121

[6] Vikatmaa, P., Juutilainen, V., Kuukasjarvi, P., et al. (2008) Negative Pressure Wound Therapy: A Systematic Review on Effectiveness and Safety. European Journal of Vascular and Endovascular Surgery: The Official Journal of the European Society for Vascular Surgery, 36, 438-448.

[7] Sakellariou, V.I., Mavrogenis, A.F. and Papagelopoulos, P.J. (2011) Negative-Pressure Wound Therapy for Musculoskeletal Tumor Surgery. Advances in Skin \& Wound Care, 24, 25-30. http://dx.doi.org/10.1097/01.ASW.0000392924.75970.b9

[8] Orgill, D.P., Manders, E.K., Sumpio, B.E., et al. (2009) The Mechanisms of Action of Vacuum Assisted Closure: More to Learn. Surgery, 146, 40-51. http://dx.doi.org/10.1016/j.surg.2009.02.002

[9] De Filippo, R.E. and Atala, A. (2002) Stretch and Growth: The Molecular and Physiologic Influences of Tissue Expansion. Plastic and Reconstructive Surgery, 109, 2450-2462.

http://dx.doi.org/10.1097/00006534-200206000-00043 